\title{
Luces y Sombras: El Rol del Derecho Civil en el Siglo XXI*
}

\section{Carlos Fernández Sessarego}

Abogado por la Universidad Nacional Mayor de San Marcos. Doctor en Derecho Civil por la Universidad Nacional Mayor de San Marcos.

Profesor Emérito de la Universidad Nacional Mayor de San Marcos.

* Dicha entrevista estuvo a cargo de Yassmin Belén Muñoz-Najar Salem, alumna de séptimo ciclo de la Facultad de Derecho de la Universidad de Lima; Natalia Begonia Ezcurra Robledo, alumna de octavo ciclo de la Facultad de Derecho de la Universidad de Lima y Miembro del Comité Editorial de la Revista ADVOCATUS; Marcial Giovanni Gutiérrez Lucar, Miembro Asociado de ADV EDITORES - Revista ADVOCATUS; y Mariana Silva Santisteban López, alumna de octavo ciclo de la Facultad de Derecho de la Universidad de Lima y Directora del Comité Editorial de la Revista ADVOCATUS. 


\title{
RESUMEN:
}

En esta ocasión, ADVOCATUS tuvo la oportunidad de entrevistar al doctor Carlos Fernández Sessarego, autor del primer libro del Código Civil, referente obligatorio en el ejercicio del Derecho Civil, y coautor de la Teoría Tridimensional. A través de las siguientes líneas, se ofrece un análisis respecto el rol del Derecho Civil en el siglo XXI, abordando el desapego de la tradición francesa patrimonialista, y el cambio hacia un Derecho Civil más humanista, junto a sus implicancias, específicamente, el daño a la persona. Finalmente, se analiza la vigencia del Código Civil de 1984, analizando las sombras del mismo.

Palabras Clave: Derecho Civil, Daño al Proyecto de Vida, Regulación Normativa, Responsabilidad Civil, Daños.

\begin{abstract}
:
On this occasion, ADVOCATUS had the opportunity to interview Carlos Fernández Sessarego, author of the first book of the Civil Code, a mandatory reference in the exercise of Civil Law, and co-author of the Three-Dimensional Theory. Throughout the following interview, an analysis is offered regarding the role of Civil Law in the 21st century, addressing the detachment of the patrimonialist French tradition, and the change towards a more humanistic Civil Law, alongside its implications, specifically, the damage to the person. Finally, the validity of the Civil Code of 1984 is analyzed, including its shadows.
\end{abstract}

Keywords: Civil Law, Damage to the Life Plan, Normative Regulation, Civil Liability, Damages.

\section{Considerando la realidad peruana y to- mando en cuenta su experiencia, ¿cuál consideraría el rol del Derecho Civil en el Siglo XXI?}

El rol del Derecho Civil en el siglo XXI, ¡qué linda pregunta! Preciosa. Imagínense, hay que tener una visión histórica, filosófica y panorámica para responder la misma. Esta pregunta no la responde un civilista, porque él ve instituciones, obligaciones. Pero responder sobre el rol, implica elevarla a un historiador, un poco filósofo.

El derecho es vida, vida humana que es regulada valiosamente, la cual se valora para saber si las conductas interferidas son justas o injustas, para crear la norma jurídica, para establecer si se permite o prohíbe la conducta valorada.

Bien, ¿cuál es el rol del Derecho en el siglo XXI? Si el Derecho es vida, el Derecho tiene que estar de acuerdo con las modificaciones y cambios de las conductas según los tiempos. Esa es la historia del Derecho. Tiene su historia precisamente por eso, pasa de etapas, de momentos, a otros; por cambios, y estamos en un momento histórico, importante en lo que se refiere al nuevo rol del Derecho.

Es un cambio revolucionario que todavía no percibimos en su totalidad. Es un cambio que proviene de la Filosofía. Cuando se preguntaba a los estudiantes, por ejemplo: "¿qué cosa es el Hombre?" "Ah, es un ser racional", contestaban. "Entonces, ¿la razón es lo que diferencia al hombre de todo los demás?"'"Sí, la razón." Este pensamiento de siglos sobre el ser humano ha variado radicalmente; y si ha variado el concepto de ser humano, tiene que variar también la visión del Derecho. Ello, porque ya no es la visión sobre un ser racional, sino que es la visión sobre un ser que es ontológicamente libre. Que su ser es libertad, no la razón. ¿No les parece un cambio extraordinario sobre el enfoque de lo que es el ser humano? ¿Y no nos damos cuenta todavía los juristas la importancia de este cambio para el Derecho? Este cambio, ese que ha influido en el Derecho, que está influyendo una renovación de muchas instituciones jurídicas, empezando por sus supuestos. Esta es una tarea que ya se inició, antes de que el ser humano fuera libre y que por esta libertad tuviera dignidad. Ya no era un objeto más, racional.

Anteriormente, en el Derecho, y sobre todo en el Derecho Civil, que es la rama fundamental, de la cual se ha desprendiendo todas las demás, decía que en este momento de cambio tenemos que tener el enfoque más humano. Antes, el Derecho giraba en torno a la protección primariamente de la propiedad. Cuando yo estudié el Código de 1936, derogado por el vigente, todo era la 
propiedad: obligaciones, contratos. El libro primero, ¿qué decía de la persona, del ser humano? Se refería a su nombre, a su domicilio y a los registros civiles. Eso era todo. Un libro mísero en conceptos, reducido, insignificante. El libro primero, el más importante del Código porque es el que se refiere al protagonista, al creador $y$ al destinatario, no decía nada. Cuando estudiábamos otras materias, nunca ningún profesor se refirió al ser humano, al que crea el Derecho para autorregularse en comunidad. De ese personaje protagonista no se decía nada. Todo era defensa de la propiedad.

¿Y de dónde nace esta defensa de la propiedad? Yo no soy historiador pero, me imagino que cuando los burgueses hacen la Revolución Francesa les interesó mantener las nuevas propiedades que habían conquistado y entonces lo más importante para ellos en ese momento era la propiedad. Esta es una hipótesis mía y punto. Pero sospecho que por ahí debe estar la cosa. ¿Por qué? Porque en el Código Civil que refleja esta revolución, el Código Civil francés de 1804, ¿sabes lo que dice de la propiedad?"La propiedad es un derecho absoluto, inviolable y sagrado." ¿Y qué dice del ser humano? Nada. El ser humano no es, no tiene derechos absolutos, sus derechos no son inviolables y no es sagrado, solo las cosas, la propiedad.

Todos los códigos copian al Código Civil francés, y por eso el Código Civil peruano con su libro primero, marca una nueva etapa. Es la etapa del personalismo, que reemplaza en prioridad a la protección de la propiedad. Ya no es la propiedad lo que el Derecho del siglo XXI protege. No, es el ser humano, $y$, luego, los instrumentos de los cuales se vale el ser humano para vivir, que es la propiedad, desde el colchón donde duermo hasta la caso donde habito.

¿Qué cosa es primero? ¿El fin en sí mismo, que es el ser humano, o sus instrumentos? Por supuesto, no hay discusión. Este es el nuevo rol del Derecho y del Derecho Civil en el siglo XXI: la protección primaria del ser humano. ¿La propiedad es un derecho absoluto? Falso. Hay derechos absolutos, todos tenemos los mismos derechos. Pero el ejercicio de los derechos está limitado. Entonces, desde el punto de vista del ejercicio de un derecho, hay limitaciones. Yo soy libre, sí. Pero estos actos no los puedo realizar. Entonces en el ejercicio del Derecho es donde existen limitaciones, regularizaciones, restricciones. Pero no en el Derecho. Decir que la propiedad es un derecho absoluto sin decir que en el ejercicio la propiedad no lo es, es un error. ¿Qué es inviolable? ¡Qué novedad! Todos los derechos son violables por naturaleza, todos. Por más que digan "se respeta la vida", pues mañana vemos que le dispararon a un sujeto y está muerto. ¿Cómo? ¿Y el derecho a la vida?”Lo violaron. Todo derecho es violable. Entonces, la propiedad no es inviolable. Y, por fin, ¿sagrada? Si sagrado hay algo, es el ser humano, según la concepción que usted tenga del ser humano, y nada más.

Entonces, ¿cuál es el rol del Derecho en el siglo $X X I$ ? El que acabo de referirme, la prioritaria protección de la persona. Estamos en un momento de transición histórica entre el patrimonialismo y en el personalismo, sin embargo todavía estamos en el patrimonialismo. Hay cambios importantes pero todavía no hemos llegado a centrarnos solo en personalismo. ¿Saben cuál es el descubrimiento que tenía que devenir? Que alrededor de los años 80 del siglo $X X$ aparece un nuevo derecho. ¡Qué curioso! El derecho más antiguo recién aparece en el año 80 del siglo XX. Bueno, empieza en algunas sentencias de los años 70 pero el estudio y la doctrina se construyen en el año 80. ¿Qué se descubre? El derecho de la persona. ¡lmagínense! Recién se descubre el derecho de la persona que debe ser prioritariamente protegido. $Y$ entonces, el derecho de la persona, el Código Civil peruano de 1984 es el primer Código en el mundo que, en el artículo 1985, introduce la protección a la persona.

Ese es uno de los méritos del Código, que tiene sus luces y sus sombras, como todo código, como toda obra humana. Pero bien, ¿cómo se avanza en este camino del momento en transición del Derecho en que vivimos? Yo tengo, pues, algo de historiador, que me gusta, algo de filósofo. Entonces, veo también desde esas perspectivas que me permiten tener un panorama más amplio.

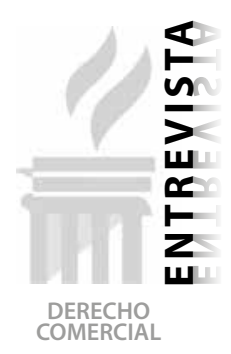

.


En los años 80, a comienzos, aparece otra figura en el Perú: el daño al proyecto de vida. Este es un descubrimiento extraordinario que va en esa dirección: recién se descubre que la libertad del ser humano podía ser dañada. Pero para eso tiene que entender usted qué es la libertad, de la cual se ha hablado siempre pero no se ha explicado qué es. Igual que la dignidad: todos hablamos de la dignidad pero no sabemos qué es. Los juristas no tienen idea, no han tenido idea de lo que es la libertad. Todos sabemos qué es la libertad, morimos por la libertad; pero cuando se nos pregunta "defina la libertad", no la podemos definir así como tampoco podemos definir a Dios. ¿Por qué? Porque la Libertad es nuestro ser, ¿cómo voy a ver el ser? ¿Cómo puedo definir mi ser? Diciendo: "Soy lo que soy, un ser libre." Pero, ¿qué es la libertad? No sé. Y la siento, la vivo; eso es lo que puedo decir. Como siento y vivo a Dios en mí, siento y vivo la Libertad, pero no la puedo definir. Esa es la libertad ontológica: tu ser. ¿Qué podemos decir de la libertad? Es un atributo. ¿La libertad? Es el decidir por sí mismo. Precisamente porque eres libre, decides por ti mismo. Esas decisiones se vuelcan a la realidad de la vida; esas decisiones son libertad también; libertad convertida en fenómeno, en acto, en conducta. Y ese acto, esa conducta, no se había descubierto hasta los años 80 que se podía dañar.

Se sabía que se podía dañar la libertad ontológica: dando muerte a la persona muere la libertad. Muere el ser con la persona, obviamente. Pero no se había descubierto que los actos y conductas libres en acto, realizándose en la realidad de la vida; esa libertad podía también dañarse. La libertad que se le llama libertad fenoménica, libertad hecha acto, hecha conducta. Libertad hecha proyecto. La libertad es proyecto, la libertad vive proyectando; $y$ esos proyectos que son permanentemente toda la vida, todos confluyen como los afluentes de un río. El proyecto de vida, cada uno escoge cómo vivir, qué vivir, qué hacer con mi vida. Es muy importante el proyecto de vida, es lo que el ser o ser libre decide vivir como ser libre, como la persona ha decidido.

Pues bien, un ejemplo: un pianista, un tenista, un cirujano pierde un brazo. ¿Qué se le ha dañado? No solamente su cuerpo, perdiendo un miembro, se les ha dañado también su proyecto. El pianista ya no podrá hacer más nunca lo que él decidió hacer toda su vida, lo que ama: el piano. El cirujano no va a poder intervenir más; y el tenista no va a poder jugar más tenis siendo, tal vez, un tenista muy importante.

Pues bien, esos son daños al proyecto de vida. ¿Cuál es el efecto de ello? Es decir, un daño a la libertad hecha conducta. Si la personalidad es fuerte, si esa persona, aparte de esta pasión por lo que hace, tiene otras pasiones - como, por ejemplo, una familia- esa persona hará lo que sea para seguir ayudando a su familia. Si es médico, será, pues, profesor de medicina, será enfermero; y si es pianista será profesor de música; y si es tenista será pues también podrá ser profesor o cualquier otra cosa. Es decir, escogen un proyecto sustituto para seguir viviendo disminuidos: su proyecto de vida se arruinó.

Hay otros más débiles, que no tienen tantos ideales. Esos se sienten que han perdido muy importante y se degradan, se dedican al vicio, a la bebida, a la droga. Y los más débiles de personalidad, los que no tienen otra pasión aparte de lo que hacen, de su profesión, llamémosle así: no tienen, familia, no tienen otros ideales, " $¿ Q u e ́$ sentido tiene mi vida? ¿Para qué vivo? ¿Para quién vivo?”

El daño al proyecto de vida se frustra, se menoscaba o también se demora. Hay un caso famoso que recogió la Corte Interamericana — de Derechos Humanos- en 1998 sobre la señora Loayza que estuvo detenida aquí en Perú por cinco años por terrorista, y a los cinco años se la absolvió'; esa mujer perdió cinco años de su vida, demoró su proyecto de vida cinco años. Se le causó un daño, también, a su proyecto.

1. Sentencia Loayza Tamayo vs. Perú disponible en: <https://www.cidh.oas.org/annualrep/99span/De\%20Fondo/ Peru10820.htm>. 
Pues bien, el rol del Derecho en el siglo XXI está clarísimo: defender de todo daño al ser humano, con prioridad. Salir de la mentalidad patrimonialista que heredamos del derecho tradicional y del Código Civil francés de 1804, que fue imitado por todos los demás códigos en la parte ideológica salvo, como les digo, hasta donde llegan mis conocimientos, el Código Civil peruano, que se refiere en su artículo 5 a los derechos del ser humano: la vida, la libertad, entre otros.

Pues bien, esta sería mi respuesta: el cambio revolucionario que se ha producido en el rol del Derecho en el siglo XXI. ¿Cuándo los percibiremos? Cuando terminemos este momento de transición.

Para terminar, porque esta es una pregunta muy importante, que merece pues algún tiempo para comprender, porque estamos muy sumergidos en el día a día como para detenernos a pensar en estos grandes problemas. Fíjense ustedes: hay por ahí hasta once innovaciones al sentido significado de instituciones creadas en la época en que no se sabía que el ser humano era un "Ser Libertad." Por ejemplo, el daño moral, porque sufre la moral. ¿Cuál moral? Entonces van donde el juez y él debería decirles cuál de las morales ha sido dañada, pues tendrán que buscar cual moral. No, la moral, además, no es parte del ser humano como tal. La moral es un conjunto de principios a los cuales el ser humano se adhiere, pero no son propios de su ser. Son principios ajenos, a los cuales el ser humano se acoge, a una moral cristiana o cualquier otra. Esto, al fin ha sido comprendido y esto es una gran satisfacción.

La Corte Suprema del Perú ya ha aceptado que el daño moral es un daño psíquico, emocional. Cualquier emoción es dañada con eso que antiguamente se llamaba moral, son todas las emociones. Emociones que con el tiempo se disipan o emociones que se convierten en otras. Sería largo que ahora me refiriera a este tema, pero es importante.

Otro tema es la famosa autonomía de la voluntad, que aparece por todos lados. "La autonomía de la voluntad", no señor, la voluntad no es autónoma. La autonomía es parte del psiquismo del ser humano, lo autónomo es la libertad; la libertad decide y la voluntad, ejecuta. Por lo tanto, no es autónoma una decisión de quien sí es autónomo. El ser humano en cuanto es libre, decide; y la voluntad y otras potencialidades del ser humano cumplen con ejecutar esa voluntad. Eso está, para mí, clarísimo y no sé si en el siglo XXII se cambie el Código y se elimine esto de la "autonomía de la voluntad".

Falso, esto es porque no se conocía qué cosa es la libertad y porque no se conocía que el ser humano es un ser libre y ya no más solo un ser racional. Porque con el chimpancé tenemos en comunidad más del $95 \%$ de genes; el chimpancé tiene voluntad, tiene sentimientos y tiene una capacidad de inteligencia reducida. El perro, tiene una inteligencia asociativa: sabe a dónde tiene que ir a comer.Y tiene voluntad:"siéntate", el perro se sienta;"corre", el perro corre. ¿Qué es eso? Lo único que le falta es libertad. Es la libertad lo que nos diferencia de los otros animales mamíferos. Somos animales mamíferos, que nos diferenciamos del resto - de nuestra especie - por la libertad. Tenemos que luchar entre la libertad, que es espiritual, y nuestras tendencias animalescas todo el tiempo. ¿Por qué me dejo llevar? Es una lucha. El ser humano vive una lucha civil constante entre sus tendencias en cuanto a animal y su calidad espiritual. Es un ser libre espiritual, porque no hay libertad sin espíritu y espíritu sin libertad. Si yo soy libre tengo que escoger.Y, ¿qué escojo? Los valores. Y, ¿qué son los valores? La vida espiritual, el amor. ¿La vida espiritual? Sí. ¿Es un valor? Sí. ¿La justicia? Sí. ¿La belleza? Sí. Entonces si yo digo libertad, digo espiritualidad y seguido de espiritualidad digo libertad. Habrá personas que no les gusta este tema pero esa es mi óptica personal.

\section{Según su opinión, ¿el Código Civil de 1984 se encuentra completamente vigente 0 adecuado a la realidad peruana? $Y$, ¿de- berían ser los juristas más receptivos a los cambios sociales?}

Hay dos respuestas simples que se pueden desarrollar. La primera, si el Derecho refleja la vida humana; el Código Civil, que es parte del derecho, debe reflejar lo que sucede en las conductas humanas del tiempo en el cual está vigente. Esa es la primera cuestión, la cual también se puede

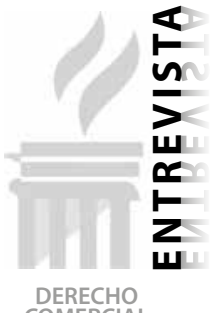

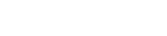

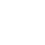


decir de otra forma: como la vida cambia aceleradamente y los códigos se cambian después de grandes esfuerzos y esperas terribles, nunca un código se adecuará a la realidad. Ni el código que se escribe en ese momento se adecua, porque no ve algunos aspectos y nace el código con algunas inadecuaciones. Por eso todo Código Civil tiene luces y sombras; y aquí me están preguntando por la parte triste, por las sombras.

Desde que se puso en vigencia el Código del 84, yo sabía que no estaba adecuado a la realidad. ¿Por qué? Porque yo me daba cuenta, por ejemplo, de que el artículo 3 estaba mal redactado. El artículo 3 se refiere a la capacidad y está escrito de una forma como si la capacidad pudiera ser puesta de lado, cuando todos tenemos capacidad y no la perdemos. La capacidad es algo inherente a nosotros. Todos somos capaces, entonces no se puede decir que la capacidad puede limitarse o restringirse. Lo que se limita o restringe es el ejercicio de la capacidad. Y si usted lee el artículo 3 , es confuso. Parece que la capacidad se puede poner de lado. Grave error, ese artículo hay que cambiarlo, y yo no pude. Ya sabía, cuando nació el código, que tenía ese defecto*.

Otro defecto terrible, el artículo 78, que se refiere a la naturaleza de las personas jurídicas. Yo sabía que ese artículo era una aberración jurídica, pero como todos los códigos del mundo tenían esa fórmula, no iban a aceptar la mía, sino la que era de todo el mundo. No hay derecho sin seres humanos, el único sujeto del derecho hasta hoy es el ser humano, individualmente o agrupadas en comunidad. Es el único sujeto del derecho, él creó el derecho para protegerse. El creador del derecho es el ser humano, para mí por eso no hay derecho natural.

El creador del derecho es el ser humano, lo creó desde los tiempos primitivos para proteger su territorio. Pero así era la realidad, ellos crearon el derecho - que era una mezcla de derecho, de moral, qué se yo-, pero allí estaban ya reglas de conducta. ¿Y quién es el que cumple el derecho? El ser humano. El ser humano es el protagonista. Es el que compra, el que vende, el que mata, el que se suicida, el que da anticipos de herencia, el deudor que entra en moratoria. El derecho es eso, relaciones entre seres humanos. El ser humano es el protagonista. Si falta el ser humano, ¿de qué hablamos? Falta el protagonista en la obra de teatro. ¿De qué obra hablamos si no hay protagonistas, si no hay actores? Y, finalmente, el ser humano crea el derecho para ser su destinatario; creamos el derecho para que nosotros mismos cumplamos lo que hemos creado. Entonces, si no hay seres humanos, no hay persona.

La persona, el ser humano, es el único sujeto del derecho. Y si vemos el artículo 78, dice que en la persona jurídica no hay seres humanos, no hay personas, y por lo tanto no hay patrimonio. Entonces, ¿qué es? Una organización que no es de personas, ¿es ideal? ¿Qué cosa es? No es nada. Qué aberración, han creado un sujeto de derecho sin personas. Eso es el artículo 78. Yo me opuse, pero mi opinión era un voto y era una comisión la que elaboró el Código y que luego lo revisó. En la comisión revisora no intervine. Entonces, no puede ser. Un día la comisión revisora del proyecto que habíamos hecho, la comisión en que yo sí intervine - la primera, la redactora-, la comisión revisora me llamó un día - para hacerme algunas consultas, seguro - y entre las consultas el tema que se trató fue "persona jurídica".Yo les volvía dar mi versión y me dijeron:"No, esto ya está aprobado y no se puede modificar. Pero le pedimos algo que usted no ha hecho como redactor del Libro Primero. Usted no ha definido las cuatro personas jurídicas que tiene el Código Civil: la asociación, la fundación, el comité — que fue una creación de un miembro de la comisión-y, la comunidad; y yo sé que los códigos no definen. Los códigos

* Dicha entrevista se llevó a cabo antes de la modificatoria al Código Civil del 4 de septiembre del 2018, la cual establece lo siguiente:

"Artículo 3.- Capacidad jurídica

Toda persona tiene capacidad jurídica para el goce y ejercicio de sus derechos.

La capacidad de ejercicio solo puede ser restringida por ley. Las personas con discapacidad tienen capacidad de ejercicio en igualdad de condiciones en todos los aspectos de la vida". 
regulan, norman: se puede o no se puede, está prohibido o está permitido. Pero no definen, es la doctrina la que define y el codificador recoge alguna versión de la doctrina. $Y$ a pesar que yo estaba contrario a que el código definiera dije"esta es la mía", ahora voy a poner a realidad lo que son las personas jurídicas. Y si ustedes leen el código y leen "la asociación" dice: "es una organización de personas." "¿Cómo? si el artículo 78 dice que no hay personas". Está en contradicción, pues señores. Y la fundación igual; y el comité, igual; y las comunidades también. Conjunto de personas, porque eso son. El artículo 78 fue creado para facilitar la vida de los negocios, para que tuvieran el privilegio de no pagar ciertos impuestos, entre otros, pero eso se puede decir de otra manera, diciendo: "Hay organizaciones de personas que van a tener estos privilegios, porque se dedican a la vida de los negocios"y se colocan los privilegios. Pero no, se dice que una persona jurídica no tiene seres humanos, y menos propiedad.

¿Qué pasó? Que la escuela alemana, la pandectística, creó esta persona justo para facilitar los negocios. La creó como una figura propia de la técnica jurídica, que no estaba en la realidad. Por eso le llamaron "persona jurídica", le pusieron "jurídica". ¿Quiere decir que las demás no somos jurídicas? No. La llamaron jurídica para decir:"Ojo, esta es una entidad que no está en la realidad." Ha sido creada por lo jurídico, por el Derecho Positivo. Pero, ¿para qué dar tantas vueltas cuando se podía definir de otras maneras? Otorgándole a la vida negocial los privilegios que quería darle la escuela pandectística alemana. Para esto hay que saber qué cosa decía la escuela pandectística y su exponente más conocido, Savigny. Y a veces, esos temas, no hay tiempo para revisarlos. Pues bien, esa es otra sombra del Código Civil.

Otra sombra está en todo lo referente a Responsabilidad Civil. Eso hay que rehacerlo. Ya no es Responsabilidad Civil. "¿Responsabilidad por qué, señor?" "Por daño." "Ah, ¿entonces a usted le interesa sólo la responsabilidad y no el daño, que es lo que causa la responsabilidad? ¿Se interesa sólo por el efecto y no la causa?"Hoy en día, la Responsabilidad Civil es parte de un nuevo Derecho que se llama "Derecho de Daños". En este nuevo Derecho, lo primero es saber qué es el daño, que el daño no está clasificado como dicen:"que en daño patrimonial, que en daño extrapatrimonial..." Esas son las consecuencias del daño. ¿Pero de qué daño? ¿Un ser humano se daña de la misma manera que un auto? No. Entonces la naturaleza del ente dañado da lugar a que sea patrimonial, la reparación extrapatrimonial.

El daño se clasifica en daño a la persona — daño subjetivo- y daño a los objetos o cosas del mundo - daño objetivo-. Cada uno, por su naturaleza tan diferente; tiene sus criterios, su técnica y su manera de reparar los daños. No es lo mismo reparar un daño a la vista, la pérdida de la vista del ser humano, que el daño a un faro de un automóvil. Entonces, ¿cómo sé yo si es patrimonial, si es extrapatrimonial? Tengo que ver el ente dañado, qué significa para el ente dañado esa pérdida y cuál es el criterio para reparar. ¿Es lo mismo reparar daños a los seres humanos que a las cosas? ¿Es el mismo criterio? Los daños patrimoniales y extrapatrimoniales son las consecuencias de un daño que hoy no se sabe qué tipo de daño es. Eso hay que cambiarlo. Todo respecto al Derecho de Daños hay que cambiarlo. Son sombras oscuras, bien oscuras.

Pues bien, en el Derecho de Daños, que yo no pude introducirlo porque tampoco lo tenía yo, como derecho orgánico, muy claro el conjunto; pero sí tenía claro que el daño a la persona no era lo mismo que un daño a las cosas, obvio.

Lo único que logré, en el último minuto, fue introducir el daño a la persona en el artículo 1985, que dice "daño a la persona y daño moral." Yo quise sacar el daño moral porque el daño moral es un daño a la persona. No es algo diferente. Pues, eso, y que lo dije antes en ese momento, no lo puede repetir. ¿Saben en qué momento se introdujo? Cuando el Ministro de Justicia nos reúne, a la comisión revisora y a dos o tres de la redactora y dijo:"Bueno. Entonces, ya. ¿Cerramos el Código para enviarlo al Poder Ejecutivo? ¿Hay algún cambio?" Yo dije: "Sí señor, hay que introducir el daño a la persona que ya está creado en Italia"“'Ya, ya, ¿están de acuerdo?"“'Sí, sí, sí".

Ya por cansancio se introdujo el daño a la persona. Un cambio tan importante, está metidito ahí

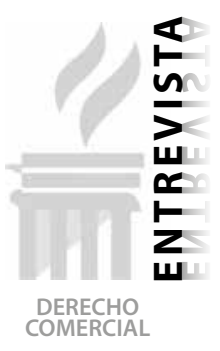

COMERCIAL 
junto al daño moral. Y el artículo 1984 solamente se refiere al daño moral cuando ese artículo debería referirse, a título, al daño a la persona. Hay que rehacer todo lo referente a Responsabilidad Civil.

Hace treinta años que persigo todas las modificaciones que hay que hacerle al Código Civil, tanto las de origen como las que han venido a través del tiempo. No hay nada, por ejemplo, sobre los hijos, sobre esta parte biogenética. No hay nada, porque llegamos tarde a eso. Empezamos en 1965 y todas estas cosas son novedosas. E Código no alcanzó a regularlas porque no estaban en la conducta de los hombres en aquel momento. Miren, en el Centro de Investigaciones de la Universidad de Lima creé una comisión de civilistas, los mejores profesores en cada rama del derecho civil, para que propusieran enmiendas. Esto que están buscando hoy, en 1984 creo. Por ahí, por ahí. Terminamos y yo le entrego, por oficio, al Doctor Carlos Torres y Torres Lara, que presidía en el Congreso o algo, y además había sido mi discípulo y yo lo conocía y lo quería, hasta que cambió de bandera. Gran muchacho, gran amigo. Le mandé un oficio. Me dijo: "Mándame todo ese proyecto."'Acá está." Nombró por ley una comisión revisora del Código Civil. Nos reunimos. Yo no estaba porque ese Congreso no me quería, yo era de otra banda. Pero, los de la comisión me nombraron relator, es decir que proponía las modificaciones que debían hacerse. Duró muy poco, vinieron las elecciones y se disolvió todo. Vino un nuevo gobierno y nombraron otra comisión.

1987, por ahí, hicimos otro proyecto los mejores civilistas de ese momento. A fines del 87 y comienzos del 88 hicimos un nuevo proyecto, muy buen proyecto. Nada. Pasaron los años y no sucedió nada. Nombraron una tercera comisión donde ya yo, ni Max Arias ni De la Puente estuvimos, por viejos. Precedida por el doctor Avendaño, hizo una cosa muy diminuta. Pero en fin, allí está. ¿Cuánto tiempo ha pasado? Más de treinta años y no se ha movido nada. ¿Por culpa de quién? De los congresistas, que han tenido los proyectos, pero habían otros intereses superiores a un Código Civil de un país. Esos son los culpables de que haya sombras y no se haya podido adecuar el Código. A mí me da mucha pena, como gestor del Código del 84, como gestor de sus modificaciones, lo he perseguido por treinta años. Yo, el autor, persiguiendo los defectos de la obra, para adecuarla a los tiempos. Eso que es el motivo de la pregunta.

Ahora hay otra comisión... ojala llegue a un proyecto. Son mis mejores augurios. Me sentiría feliz de que el Código que contribuí a elaborar se pusiera al día, que vengo persiguiendo hace treinta años desde el día siguiente al que entró en vigencia. Tan fastidiado estaba que el día que se pone en vigencia el Código Civil yo no asistí a la ceremonia.

Yo no quiero cargar con los defectos, como el artículo 78 o el 3. Y algunos otros que hay que modificar: el 17, el 14, entre otros. Creo que en el año 2009 cumplió 30 años de vigencia el Código. Ahora estamos en el año 2018, saquen cuentas, tiene más de 30 años de vigencia el Código. Esa es la razón, esas son las sombras que hay. Algunas ya nacieron con el Código, como les he referido.

Todos los Códigos cambian porque cambia la vida. Hay nuevas figuras y nuevas conductas que hay que regular en los códigos. No es una novedad, es algo propio de los códigos y propio de la vida que los códigos reflejan y regulan

Pues bien, vuelvo al comienzo: en todo Código hay luces y sombras. Si la vida es conducta, los códigos regulan las conductas y las conductas van cambiando; pues los códigos deben ir cambiando de acuerdo a las conductas. Hay nuevas conductas que aparecen y que hay que regular, como todas estas de la biogenética, que no alcanzamos a eso. Eso sería la visión que tengo sobre el tema de las luces y las sombras, a ver si el próximo Congreso pregunte por las luces del Código, que son muy importantes históricamente. Es un Código que ha abierto caminos nuevos, y lo han dicho los profesores extranjeros, no los peruanos. Es un Código que ha sido alabado y tomado como modelo. Y, por ejemplo, el Daño al Proyecto de Vida, ya se ha introducido en el Código Civil y Comercial Argentino del año 2014-2015. jAhorita! Ya está en un código, lo reconoce la Corte Interamericana, está en la doctrina, está en Francia, en Italia, está en muchas partes. Hay foros que estudian el Daño al Proyecto de Vida, esta novedad increíble que se ha presentado. ¿Y qué cosa es el Proyecto de 
Vida? Pues bien, como yo les digo, yo estudié Filosofía, y entonces, estudiando a Jean Paul Sartre, él se refiere ya al Proyecto de Vida. Y yo descubrí el Proyecto de Vida como estudiante de Filosofía en la Facultad de Letras que seguí junto al Derecho - yo estuve en dos facultades-y dije:" ¡Qué maravilla el Proyecto de Vida! ¡Qué interesante! La libertad es proyecto". Entonces en mi tesis de bachiller en Derecho, en el año 50, aparece el Tridimensionalismo jurídico por eso. Cuando el profesor dijo que habían tres objetos del estudio del Derecho dije: "¡Qué locura! Ninguna ciencia estudia tres objetos al mismo tiempo"Y me puse, pues, a trabajar en eso. Y salió la tesis: "Bosquejo para una Determinación Ontológica del Derecho". Es decir, ¿Qué cosa es el Derecho? Porque si hay tres, hay que decir cuál de los tres es el objeto de su estudio, o que objeto de estudio hay diferente. Pues así fue como aparece esta figura.

\section{Considerando su experiencia y grandes re- conocimientos a nivel internacional, ¿Qué cree usted que se debe tener presente en la enseñanza universitaria del Derecho Civil?}

Lo más importante para mí es que el profesor sienta el Derecho, que no permanezca frío e indiferente frente a la justicia como a la injusticia. Que se alegre con la justicia y que se indigne con la injusticia. Esos que parecen fríos e indiferentes frente a la injusticia, esos no pueden ser juristas ni abogados. Yo para entrar a una escuela de Derecho, ¿saben qué haría? Haría un test para conocer cuál es su actitud frente a una injusticia, cuál es su reacción emocional. Eso es muy importante. El abogado tiene que ser también un poco psicólogo. Yo, en vez de haber estudiado Derecho, hubiera estudiado psicología.

Entonces, para una escuela tiene que haber un León Barandiarán, si hubiera tenido León Barandiarán ideas diferentes. Fue un sabio que conocía todo, pero no creo nada. La única escuela que puede haber es la de Fernández Sessarego, que ha creado una nueva visión del Derecho y que tengo discípulos que siguen mi visión, mientras los antiguos siguen la tradicional.

Les voy a contar una anécdota para que sepan cómo me ven fuera de Perú. Bueno, recién me he dado cuenta de que soy mundialmente conocido. Sí, sobre todo por el Daño al Proyecto de Vida y por el Tridimensionalismo. Yo también he creado el nuevo concepto de identidad y el nuevo concepto de la finalidad del Derecho, que no es la justicia sino la libertad. La justicia está al servicio de la libertad, organizando la sociedad, de tal forma de que cada ser humano en cuanto a ser libre tenga oportunidad. Entonces la justicia que se llama social, tiene que ver con que la mayoría de las personas tengan oportunidades. Aparte, claro, de la justicia interpersonal de los conflictos que hay entre dos o tres personas, hay justicia social, de la cual poco se habla. Dicen:"Oh, este es comunista, justicia social", y demás, tantas cosas. Pero es necesario: el Derecho persigue la justicia social, ¿ Para qué? ¿Al servicio de qué? De la libertad. ¿Para qué quiero yo justicia? ¿Para defender mis instintos de venganza? No. Es para organizar la sociedad, para que haya paz y libertad. Contribuir a ambas cosas.

Les iba a contar una anécdota. A mí me han impreso dos libros en la Argentina, en el año 92. Uno de ellos se llama "El Derecho a la Identidad", en el cual me preocupo mucho del transexual y digo que lo transexual es un drama existencial. Hay una inadecuación en su cuerpo, en su modo de vivir.Y, ¿Qué es más importante? ¿El cuerpo o el no vivir? El no vivir. Entonces, al transexual hay que reconocerlo en lo que es, como es. Y no en sus otros elementos. Yo defiendo a los transexuales, no he entrado en el problema ya de los géneros. Es una realidad, está en la conducta. Hay que respetarla y regularla, punto. Te guste o no te guste.

Bueno, les digo que con Astrea, la gran editorial argentina, ya tengo una relación. El otro libro es "Abuso del Derecho", que acaba de salir la tercera edición después de 24 años. Es un libro que escribí en el año 90 y se publicó en el 92. La primera edición peruana es de 1999, esta es la tercera. Es un libro ya clásico, está en Amazon, eso donde venden libros. Bueno, pero vino un representante de Astrea en 2014. Me llama, me dice: "Quiero conversar con usted. Doctor, queremos editar un libro suyo." "Perdón", les digo. El que estoy escribiendo que va a salir en estos meses se llama Derecho Médico, es un tomo de 1500 páginas hecho con una estudiante mía de la de Lima que ahora es profesora, Olenka Woolcott, me ha ayudado. Porque una cosa es que yo tenga un derecho médico, no sé por qué me metí ahí. Antes había hecho un libro sobre el consentimiento informado, para los médicos el ser un paciente no es ser un objeto. Aquí se le invade su cuerpo sin pedirle permiso. Si para

(n)

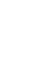


entrar a un domicilio hay que pedirle permiso al juez, con mayor razón para ingresar al cuerpo de una persona. Entonces los médicos tienen el deber de informar y de pedir el consentimiento, ya sea para hacer un tratamiento o una intervención. Hice un libro de 700 páginas que se llama "La Responsabilidad Civil del Médico y el Consentimiento Informado." Pero más que la Responsabilidad Civil del Médico, eso lo puso el editor para marketing, ahí veo que la libertad tiene que interesar a la medicina. $Y$ ya los médicos lo han aceptado, en teoría. No en la práctica, en la práctica lo burlan. Y desde que salió mi libro, todas las clínicas, los hospitales y los laboratorios lo hace firmar a usted un papel en que dice que ha sido informado y que da su consentimiento antes que todo esto suceda.

Pues bien, viene el señor de Astrea y me dice, y yo le digo: "Señor, tengo este libro Derecho Médico que ya está en las manos de otra editora $y$ tengo otro que es estoy trabajando ahora que es el Daño al Proyecto de Vida", porque todo esto ha sido sobre la base de treinta ensayos que he ido produciendo sobre el Daño al Proyecto de Vida conforme avanzaba. Y esos artículos, esos ensayos, esos son los que consultan en todo el mundo sobre la base del cual el Daño al Proyecto de Vida se ha extendido ya mundialmente. "Entonces, ¿Qué quiere usted editar?", le digo. "Un libro que usted escribió en 1990". "Ah, ¿sí? ¿Y lo quiere reeditar?" Astrea no reedita, es una de las tantas editoriales importantes que reedita primeras ediciones o traducciones de libros importantes en idioma extranjero. "Mire usted, pero que raro. $¿ Y$, por qué quieren reeditar este libro del año 90?" El doctor me dice: "El libro se llama "Derecho y Persona", salieron 4 ediciones peruanas". Y me olvidé, porque como tengo 17 libros escritos, ya me olvido de lo que he hecho y voy a lo nuevo. Ahora voy por el 18 , si Dios me da vida. "Ah, me dice, porque este libro, Doctor, es una nueva visión del Derecho suya. $Y$ este es un libro que no puede perderse por eso. Lo reeditamos, que es un libro histórico, emblemático y clásico. Una nueva visión del Derecho. Derecho y persona. Y ahora estoy luchando para que salga la sexta edición; porque ese libro, en la quinta edición circuló por todo el mundo, menos en Perú. Porque cuesta dólares, y aquí no le interesa al mercado peruano.

Entonces la quinta edición no ha circulado en Perú. Y dirá usted, ¿Cómo? Este argentino, un editor, no puede discriminar. Ha escuchado muchas voces, le han dicho: "Fernández Sessarego ha creado un nuevo Derecho en base a la Libertad, empezando por el Daño a la persona, el Daño al Proyecto de Vida y once innovaciones que tiene. Es un nuevo Derecho, es el Derecho que está en la transición, es una muestra de que estamos definitivamente en una transición. Porque ese libro difiere del pasado. Entonces, esa es la razón por la que está este libro vigente. $Y$, con gran pena, no circula en Lima, en el Perú en general no circula. Y fíjense ustedes que la Universidad Nacional de Buenos Aires me ha hecho Doctor Honoris Causa. Muy difícil, la mejor universidad de Latinoamérica hoy, que haga Doctor Honoris Causa. ¿Y por qué? Porque ha aportado teorías al mundo y al derecho argentino. Mi libro sobre la identidad cambió todo, el Daño al Proyecto de Vida lo he incorporado. El tema de los transexuales ha cambiado la jurisprudencia siguiendo mi tesis. Ahí está la resolución, me nombran Doctor Honoris Causa por haber creado doctrinas nuevas mundiales y que han servido a la Argentina. Pero más importante que eso y tampoco está publicado, se los cuento a ustedes casi en secreto: la Asociación de Civilistas Italianos que reúne a los mejores civilistas, en el año 2013 precedido por el maestro Guido Alpa, me nombra miembro honorario de la Asociación de Civilistas Italianos por la contribución que yo les he dado a ellos. La primera contribución latinoamericana a Europa. De Perú, el primer país. En España me conocen como "el Sudamericano".

Yo, sin querer queriendo como el Chavo del ocho, me he vuelto así. Por la imaginación, creadora. Porque he creado cinco cosas nuevas que los demás no. Si hubieran estudiado Filosofía estuvieran preparados los juristas, para cambiar las cosas que yo he cambiado a partir de la Filosofía. Si yo no hubiera estudiado Filosofía no habría hecho nada, probablemente. Porque me faltó la fuente. 